\title{
Correction to: Potential role of IncRNA-TSIX, miR-548-a-3p, and SOGA1 mRNA in the diagnosis of hepatocellular carcinoma
}

\author{
Published online: 2 May 2019 \\ (c) Springer Nature B.V. 2019

\section{Correction to: Molecular Biology Reports https://doi.org/10.1007/s11033-019-04810-x}

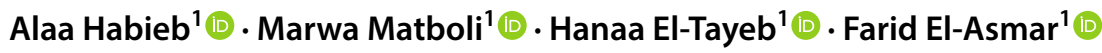

The original publication has been updated. The family name of Alaa Habieb contained a typo that has now been corrected.

Publisher's Note Springer Nature remains neutral with regard to jurisdictional claims in published maps and institutional affiliations.

The original article can be found online at https://doi.org/10.1007/ s11033-019-04810-x.

\footnotetext{
Marwa Matboli marwasayed472@yahoo.com;

DrMarwa_Matboly@med.asu.edu.eg

Hanaa El-Tayeb

https://www.researchgate.net/scientific-contributions/214231

7463_Hanaa_El-Tayeb

Farid El-Asmar

https://www.researchgate.net/profile/Mohamed_Elasmar https://scholar.google.com/citations?

user $=$ dUmWTfEAAAAJ $\&$ hl $=$ en

1 Medical Biochemistry and Molecular Biology Department,

Faculty of Medicine, Ain Shams University, Abbassia,

Cairo, P.O. Box 11381, Egypt
} 